\title{
TRABALHADOR IMIGRANTE EM CONDIÇÃO \\ DE IRREGULARIDADE
}

\section{As sanções do Estatuto do Estrangeiro brasileiro e a abordagem baseada em direitos da OIT}

\section{Pedro Augusto Gravatá Nicoli}

Mestre em Direito do Trabalho pela UFMG. Advogado.

Recebido em: 23.08.2011

Área do Direito: Trabalho; Constitucional

Resumo: 0 exame do trabalho prestado por imigrante em condição de irregularidade migratória revela a disparidade de posições existentes a respeito da questão. De um lado, ordens jurídicas nacionais de caráter meramente repressivo silenciam sobre a especificidade da questão trabalhista ou simplesmente privam trabalhadores imigrantes de proteção como forma de sanção e inibição dos movimentos migratórios. De outro, a normativa internacional de direitos humanos dedica-se à matéria, proclamando a necessidade absoluta da proteção em relação ao trabalho prestado. Nesse cenário, o ensaio propõe um co-
ABSTRACT: The analysis of the work rendered by immigrants in an irregular migratory condition reveals an existing disparity of positions on the issue. On one hand, national legal orders with merely repressive characteristics are silent on the specificity of the labour question or simply deprive migrant workers from protection, as a form of punishment and inhibition of migration. On the other hand, international human rights rules are dedicated to the matter, declaring the absolute necessity of protection in relation to the work performed. In this scenario, the essay proposes a critical comparison between the 
tejo crítico entre o marco regulatório da imigração no Brasil, consolidado pelo Estatuto do Estrangeiro, e a abordagem da questão no âmbito da Organização Internacional do Trabalho (OIT), para concluir pela necessária proteção da dignidade do trabalhador, que não pode ser preterida.

Palavras-chave: Imigração - Trabalhador imigrante - Estatuto do Estrangeiro - Proteção trabalhista - OIT. migration laws in Brazil, consolidated by the Statute of the Foreigner, and the approach of the issue by the International Labour Organization, to conclude in the direction of the necessary protection of the dignity of the worker, which cannot be adjourned.

KEYWORDS: Immigration - Migrant worker Brazilian Statute of The Foreigner - Labour protection - ILO.

SumÁrio: 1. Introdução - 2. A condição de irregularidade migratória no direito brasileiro - 3. As sanções do Estatuto do Estrangeiro para os imigrantes em condição de irregularidade 4. A abordagem baseada em direitos da OIT - 5. A Convenção 143 da OIT: proteção de todos os trabalhadores migrantes -6 . Conclusão - 7. Referências bibliográficas.

\section{INTRODUÇÃO}

Não é difícil constatar a relevância do tema das migrações internacionais na contemporaneidade. Isso porque se está em um terreno de recorrentes e graves afrontas à dignidade da pessoa humana, sobretudo no que toca ao trabalho e aos desafios relacionados à proteção justrabalhista dos chamados imigrantes não documentados. Antônio Augusto Cançado Trindade percebe o problema em sua dimensão amplificada, no contexto da propagandeada "globalização", apresentando aguçada crítica:

"Em tempos da chamada 'globalização' (o neologismo dissimulado e falso está na moda hoje em dia), as fronteiras se abriram para o capital, bens e serviços, mas, infelizmente, se fecharam para os seres humanos. O neologismo, que sugere a existência de um processo que abrange todos e do qual todos participariam, na verdade, esconde a fragmentação do mundo contemporâneo, e a exclusão e marginalização social de segmentos cada vez maiores da população. O progresso material de alguns se fez acompanhar pelas formas contemporâneas (e clandestinas) de exploração do trabalho de muitos (a exploração dos imigrantes em situação irregular, prostituição forçada, tráfico infantil, trabalho forçado e escravo), em meio ao aumento da pobreza e da exclusão e marginalização social."

1. Cançado Trindade, Antônio Augusto. Voto concorrente. Condición jurídica y derechos de los migrantes indocumentados. Opinião consultiva OC-18/03. Corte 
Há, além disso, situações de interação problemática entre migrantes irregulares e sociedades receptoras, sob a influência de fatores de complicação como racismo e xenofobia. Ressalta Teresa Sales: "As migrações ilegais ou clandestinas têm sido foco de atenção dos organismos de foro internacional sobretudo a partir dos anos 70 , quando as migrações clandestinas se manifestam com mais vigor, gerando movimentos de intolerância e discriminação contra os imigrantes e suas famílias". ${ }^{2}$

Nesse contexto, o exame do tratamento dispensado aos imigrantes em condição de irregularidade revela que há posicionamentos bastante díspares, que refletem na forma como é percebida - garantida ou privada a proteção justrabalhista desses indivíduos. A marcha de recrudescimento das legislações ao redor do mundo é notória, sendo que as sanções àqueles que descumprem a legislação migratória cumpre papel central como política inibitória dos movimentos migratórios em si. Ao mesmo tempo, organismos internacionais, como a OIT, sinalizam no sentido da indispensável percepção da condição à qual esses indivíduos estão sujeitos e à necessária proteção de seus direitos essenciais, como a proteção ao trabalho prestado.

Analisar-se o trabalho prestado pelos imigrantes é imprescindível ao estudioso do tema, vez que se pode identificar em quase todo fluxo de pessoas no plano internacional a marca de relações que tenham por objeto o trabalho humano. Fronteiras nacionais são cruzadas quase sempre no intento da busca por melhores condições de vida, o que é, regra geral, mediado pelo trabalho. Isso porque, afinal, o trabalho é a alavanca de todas as realizações daquilo que

Interamericana de Direitos Humanos. São José da Costa Rica, 17.09.2003. Disponível em: [www.corteidh.or.cr/docs/opiniones/seriea_18_esp.pdf]. Acesso em: 14.07.2011. No original: "En tiempos de la así-llamada 'globalización' (el neologismo disimulado y falso que está de moda en nuestros días), las fronteras se han abierto a los capitales, bienes y servicios, pero se han tristemente cerrado a los seres humanos. El neologismo que sugiere la existencia de un proceso que abarcaría a todos y del cual todos participarían, en realidad oculta la fragmentación del mundo contemporáneo, y la exclusión y marginación sociales de segmentos cada vez mayores de la población. El progreso material de algunos se ha hecho acompañar por las formas contemporáneas (y clandestinas) de explotación laboral de muchos (la explotación de los migrantes indocumentados, la prostitución forzada, el tráfico de niños, el trabajo forzado y esclavo), en medio al aumento comprobado de la pobreza y la exclusión y marginación sociales". Tradução do autor.

2. SAles, Teresa. Brasil migrante, Brasil clandestino. Revista São Paulo em Perspectiva, n. 8(1), p. 112. 
se pode denominar "cultura humana", como bem pontua Antônio Álvares da Silva. ${ }^{3}$

Assim sendo, o presente artigo tratará da diferença essencial ainda existente na percepção do trabalhador imigrante pelo Estatuto do Estrangeiro brasileiro e pelas normas da OIT que tratam do tema, com vistas a fornecer um breve panorama no qual se possa pleitear a incidência de uma regulação mais humanizada, que não perca de vista a dimensão da dignidade do imigrante indocumentado e a necessidade de proteção do trabalho por ele prestado.

\section{A CONDIÇÃO DE IRREGULARIDADE MIGRATÓRIA NO DIREITO BRASILEIRO}

A definição mais ampla de migração irregular, tomada em relação ao país de origem e destino, bem como aos bens jurídicos envolvidos, é a sintetizada por Eduardo Geronimi:

"As migrações irregulares podem ser definidas como todo movimento internacional que tem lugar fora do marco regulamentar dos países de envio, recebimento, de ambos (...) ou de trânsito. Por definição, a migração irregular é o resultado de uma legislação promulgada para controlar os fluxos migratórios (...), e é uma violação - ou delito, no sistema penal das legislações nacionais contra a soberania do Estado".

$\mathrm{Na}$ perspectiva do direito interno, um imigrante pode ser considerado em condição de irregularidade migratória no Brasil quando não obedece aos requisitos da legislação aplicável (nomeadamente a Lei 6.815/1980, o Estatuto do Estrangeiro) em relação à entrada, permanência e/ou atividades desempenhadas no território nacional. A ordem jurídica pátria estabelece uma série extensa de condições para que a imigração se dê em perfeita consonância com o que exige o país, visando atender, nos termos do art. $2 .^{\circ}$ do Estatuto, "à segurança nacional, à organização institucional, aos interesses políticos, sócioeconômicos e culturais do Brasil, bem assim à defesa do trabalhador nacional".

3. SILVA, Antônio Álvares da. Flexibilização das relações de trabalho. São Paulo: Ed. LTr, 2002, p. 19.

4. Geronimi, Eduardo. Aspectos jurídicos del tráfico y la trata de trabajadores migrantes. Programa de Migraciones Internacionales. Genebra: OIT, 2002, p. 4. No original: "Las migraciones irregulares pueden definirse como todo movimiento internacional que tiene lugar fuera del marco regulatorio de los países de envío, de recepción, de ambos (...), o de tránsito. Por definición, la migración irregular es el resultado de la legislación promulgada para controlar los flujos migratorios (...), y es una infracción - o delito, según el sistema penal de las legislaciones nacionales - contra la soberanía del Estado". Tradução do autor. 
Quanto à entrada, estará em condição de irregularidade migratória aquele estrangeiro que não portar o visto adequado ao adentrar o território nacional. ${ }^{5}$ A este primeiro grupo o Estatuto do Estrangeiro denomina imigrante "clandestino" ${ }^{6}$ (cf. art. 125, I, da Lei 6.815/1980). Em relação à permanência, a irregularidade se verificará quando o imigrante não portar visto algum ou, uma vez vencido o prazo de seu visto, permanecer no país. A estes a lei denomina "irregulares" (art. 125, XII). Por fim, também se considera irregular aquele que exerce atividade incompatível com o tipo de autorização que lhe garante seu visto, como, por exemplo, o portador de visto de turista que executa atividade remunerada. São os chamados "impedidos", conforme texto da Lei 6.815/1980 (vide, por exemplo, art. 125, VII).

Há que se destacar, também, o que dispõe o art. 38 do Estatuto do Estrangeiro, a afetar diretamente o destino dos imigrantes em condição de irregularidade. Estabelece o dispositivo ser "vedada a legalização da estada de clandestino e de irregular, e a transformação em permanente, dos vistos de trânsito, de turista, temporário (art. 13, I a IV e VI) e de cortesia". Percebe-se muito claramente que tal disposição alinha-se ao perfil essencialmente repressivo do Estatuto no trato das imigrações irregulares.

E toda a disciplina que em relação à admissão de migrantes abraça a mesma lógica, numa visão utilitarista e de segurança de fronteiras, apartada do viés dos direitos humanos, legatária de uma inspiração autoritária e da concepção de mundo do momento em que o Estatuto entrou em vigor.

\section{As SAnções do Estatuto do Estrangeiro para os IMigrantes em CONDIÇÃO DE IRREGULARIDADE}

São essencialmente três as medidas sancionadoras de expatriação compulsória previstas na ordem jurídica brasileira: a deportação, a expulsão e a extradição. Interessa ao presente ensaio especialmente a figura da deportação,

5. Existem hipóteses de dispensa de visto, como o caso da dispensa de visto de turista com base em reciprocidade, prevista no art. 10 da Lei 6.815/1980.

6. A inadequação técnica da expressão imigrante clandestino (ou imigrante ilegal), por traduzir a esdrúxula noção de "pessoal ilegal", além de seu peso ideológico, faz com que esta não mereça uso científico. Dá-se, aqui, preferência a expressões mais acuradas, como imigrante em condição de irregularidade, imigrante não documentado e outras expressões que explicitam a irregularidade restrita à condição migratória. De todo modo, a redação da Lei 6.815/1980, tal como está hoje, mantém a infeliz alcunha "imigrante clandestino". 
vez que "tanto a extradição como a expulsão pressupõem a prática de delito criminal", ${ }^{7}$ como sintetizado por Miguel Florestano. O mesmo autor completa, asseverando que "para que se verifique a primeira (extradição) o delito deve ocorrer no território estrangeiro e, para a segunda (expulsão), a prática do crime tem de ocorrer em solo nacional". ${ }^{8}$ Ou seja, a expulsão e a extradição são figuras não correlacionadas com uma condição de irregularidade migratória em si, que é o objeto aqui em pauta. ${ }^{9}$

Já a deportação é definida no próprio Estatuto do Estrangeiro, como medida que consiste na saída compulsória do estrangeiro (art. 58), nos casos de entrada ou de estada irregular, sem retirada voluntária (art. 57). Deporta-se, também, o trabalhador fronteiriço que passe a residir irregularmente no país (art. 21, $\S 2 .^{\circ}$ ), o estrangeiro que tente burlar a inspeção de entrada (art. 24) ou que desempenhe atividade vedada para o tipo de visto que porta (art. 98 e ss.).

Desse modo, o trabalhador imigrante em condição de irregularidade tem como sanção máxima prevista na ordem jurídica brasileira a deportação. Toma-se a expressão "condição de irregularidade", aqui, de maneira ampla e genérica, a abarcar irregularidade de entrada ("clandestinos", na expressão da lei), estada irregular ("irregulares") e trabalho irregularmente executado ("impedidos"). Àqueles ditos "clandestinos" e aos "impedidos" a deportação é imediata (art. 125, I e VIII do Estatuto do Estrangeiro). Já aos chamados "irregulares" a ordem jurídica garante um prazo para a saída voluntária, cominando a pena da deportação no caso de descumprimento, além de multa proporcional aos dias de estada irregular (art. 125, II do Estatuto).

Percebe-se, especialmente aqui, que a legislação brasileira ainda encampa uma postura de tratamento à imigração irregular como questão de mera repressão a infratores, mediante a imposição da penalidade de deportação, sem prever auxílio a possíveis vítimas, não expressando maiores preocupações com as proteções que garantam a condição de dignidade desses indivíduos que, por muitas vezes, por exemplo, são alvos de esquemas de tráfico de pessoas.

7. Florestano, Miguel. Da deportação. In: Freitas, Vladimir Passos de (org.). Comentários ao Estatuto do Estrangeiro e opção de nacionalidade. Campinas: Millennium, 2006, p. 140.

8. Idem, p. 140.

9. Um imigrante em condição de irregularidade pode, naturalmente, cometer ilícito penal no país, sem qualquer correlação com o seu status migratório. Nesses casos, contudo, o crime cometido não diz respeito à condição jurídica de imigrante indocumentado, pelo que não se relaciona com o objeto aqui proposto. 
Parece pertinente, assim, a queixa de Rosita Milesi sobre a pena de deportação na legislação brasileira:

"Uma legislação que apresenta tais características e, sobretudo, o extremo rigor com que esta é aplicada, merece ser revista não apenas em aspectos ou disposições isoladas. Comporta que se repense a convivência da sociedade como um espaço de horizontes universais, onde vivem seres humanos portadores de valores, de contributos, de riquezas e de dignidade que ultrapassam as fronteiras da nacionalidade e dos limites geográficos de um país." 10

Não se pretende, por óbvio, que não existam sanções migratórias. A crítica que se faz, todavia, é ao tratamento exclusivamente repressor, aliado a requisitos discriminatórios para a obtenção de vistos. Não há dúvida que o ato de desobedecer à ordem jurídica e adentrar um país sem a devida autorização é grave. É violada a soberania nacional, em conduta atentatória à própria autonomia do Estado em estabelecer normas de controle migratório. A sanção, desta maneira, existe como resposta à violação e em favor da tentativa de recomposição da ordem estabelecida. É a realidade coercitiva do Direito, reconhecida por Edgar de Godói da Mata Machado, em clássica lição:

"Negar a presença concreta da coerção na ordem jurídica seria assumir atitude simplesmente utópica. A coerção é fruto das condições existenciais do homem. (...) Sempre existirão na sociedade aqueles protervi et ad vicia proni, cujas ameaças devem ser coibidas pela força e pelo medo."11

Em relação aos direitos trabalhistas de imigrantes que trabalhem irregularmente, coloca-se a controvérsia. O Estatuto do Estrangeiro é omisso (em verdadeiro silêncio eloquente), não prevendo as consequências da irregularidade migratória para contratos de emprego eventualmente celebrados pelo imigrante. Frise-se, assim, que as sanções que a legislação migratória prevê são adstritas à questão da condição da própria imigração, não se impondo a privação de direitos trabalhistas como forma de punição à irregularidade migratória, ou mesmo como política de inibição.

Em tese, seria possível conceber-se a negativa da proteção trabalhista como forma de sancionar indivíduo em condição de irregularidade, pela

10. Milesi, Rosita. O Estatuto do Estrangeiro e as medidas compulsórias de deportação, expulsão e extradição. Centro Scalabriniano de Estudos Migratórios. Maio de 2004. Disponível em: [www.migrante.org.br/artigo_deportacao_expulsao.doc]. Acesso em: 10.08.2011.

11. Mata Machado, Edgar de Godói da. Direito e coerção. São Paulo: Unimarco, 1999. p. 244. 
ilegalidade de sua conduta ao adentrar no país. Da mesma forma, poder-seia reconhecer a penalização por esta via como tentativa de coibir a prática da imigração ilegal, vez que o imigrante deixa de gozar dos direitos trabalhistas que lhe seriam concedidos em situação de regularidade. Tal posição, contudo, há de ser criticada em razão da pertinência sistêmica da sanção pretendida, considerando, sobretudo, as conhecidas linhas estruturantes de proteção cunhadas pelo Direito do Trabalho no país.

Quanto às diretrizes fundamentais do Direito do Trabalho, não são necessárias delongas, bastando rememorar a prevalência, no ordenamento jurídico brasileiro, de princípios como o do valor social do trabalho (art. 1. ${ }^{\circ}$, IV da CF/1988), da dignidade da pessoa humana (art. 1. ${ }^{\circ}$, III da CF/1988) e da igualdade (art. 3. ${ }^{\circ}$, IV e art. 5. ${ }^{\circ}$, caput, da CF/1988). Tais postulados devem orientar o tratamento jurídico do trabalho em si, exercido no território nacional, a despeito de irregularidades formais.

Por isso também é válida a crítica quanto à negativa de efeitos trabalhistas próprios ao contrato de emprego eventualmente celebrado por imigrante não documentado. A disciplina jurídica do trabalho efetivamente prestado distingue-se daquela destinada à entrada e permanência de estrangeiros no país. Irregularidades que atinjam a condição do imigrante serão sancionadas com as categorias normativas da legislação aplicável (no caso, a Lei 6.815/1980, Estatuto do Estrangeiro).

Ou seja, a ausência de proteção justrabalhista ao trabalhador imigrante indocumentado, como forma de sanção à sua condição subjetiva de irregularidade, não parece condizente com os preceitos do ordenamento jurídico brasileiro e com o caminhar de maturação dos marcos de proteção ao trabalho humano na perspectiva dos direitos humanos e do Direito Internacional do Trabalho, como se verá mais detalhadamente adiante. Por isso, negar ao trabalhador os direitos trabalhistas decorrentes da relação de emprego firmada (mesmo que não de forma expressa e regular) como forma de sancionar um ilícito da ordem do Direito Internacional, não parece razoável.

Isso não significa, repita-se, uma negativa à função repressiva do Direito devido à violação de seus postulados. Tampouco há um sentido de condescendência ou intento enaltecedor da imigração irregular. Por óbvio, o equilíbrio e a pertinência das sanções são fundamentais para que se alcancem padrões justos e humanizados de tratamento a indivíduos em alguma condição de vulnerabilidade.

Assim, é fundamental tomar a questão em sua dimensão humana, analisando-a de forma diuturna e não alarmista, sempre nos parâmetros jurídicos que a devem formatar. 
Ainda no aspecto trabalhista, noticie-se que o PL 5.655/2009, do Novo Estatuto do Estrangeiro, a tramitar no Congresso Nacional, inclui, em seu art. 5. ${ }^{\circ}$, parágrafo único, a seguinte disposição:

"Parágrafo único. São estendidos aos estrangeiros, independentemente de sua situação migratória, observado o disposto no art. . $^{\circ}$, caput, da Constituição:

I - o acesso à educação e à saúde;

II - os benefícios decorrentes do cumprimento das obrigações legais e contratuais concernentes à relação de trabalho, a cargo do empregador; e

III - as medidas de proteção às vítimas e às testemunhas do tráfico de pessoas e do tráfico de migrantes." 12

Assim, percebe-se que a proposta da nova lei acolhe a diretiva da promoção de direitos humanos também aos imigrantes em condição de irregularidade, não lhes privando de padrões mínimos de proteção como forma de punição por um ilícito migratório. Por outro lado, mantém as punições para a prática de irregularidades no plano das migrações, como a deportação.

Do ponto de vista das sanções, o caminho do equilíbrio entre controle e fiscalização de fronteiras, acessos e estadas com a garantia de um patamar mínimo de direitos atinentes à dignidade humana se revela como a inclinação das reformas legislativas e políticas da matéria no Brasil. Diante dos desenvolvimentos normativos constitucionais e internacionais, esta parece ser uma saída que apazigua o exercício da soberania nacional com o valor social do trabalho e a proteção universal da pessoa humana.

\section{A ABORDAGEM BASEADA EM DIREITOS DA OIT}

A OIT tem uma abordagem própria da questão, consolidada em instrumentos normativos e estudos, que contrastam sensivelmente com a forma como ordenamento jurídico brasileiro lida com o tema. Esse contraste com legislações nacionais, aliás, reforça a relevância da matéria para OIT e afiança necessidade de uma abordagem humana para a questão, colocando-a nas pautas de discussão prioritárias da instituição. Prefaciando um detalhado relatório de práticas e princípios cuja adoção no trato das migrações é recomendada, o Diretor Geral da OIT, Juan Somavia, indica a dimensão da problemática:

12. O PL 5.655/2009 está disponível em: [www.planalto.gov.br/ccivil_03/Projetos/ PL/2009/msg 507-090702.htm]. Acesso em: 05.07.2011. 
"Muitos trabalhadores migrantes, especialmente trabalhadores menos qualificados, experimentam graves abusos e exploração. (...) Em face dos obstáculos cada vez maiores que se levantam para cruzar fronteiras, o crescimento da imigração irregular e o tráfico de seres humanos constituem os grandes desafios para a proteção dos direitos humanos e trabalhistas." ${ }^{13}$

Perceba-se que, diante deste grave quadro, a OIT enfatiza, no citado relatório, a necessidade daquilo que denomina um rights-based approach to labour migration, ou seja, uma abordagem baseada em direitos para a imigração laboral, como alternativa à via da repressão exclusiva. Necessário esclarecer que não se pleiteia a inexistência de fiscalização e controle, mas que se dê preferência ao desenvolvimento de políticas que prestigiem a dimensão humana envolvida nas migrações irregulares.

Compreender os movimentos migratórios ditos clandestinos em suas causas de origem e reflexos para os Estados envolvidos e para as pessoas, de modo a consolidar e implementar este rights-based approach é tarefa de extrema complexidade. Leituras simplificadoras tendem a ressaltar, de maneira muitas vezes distorcida, aspectos isolados como a soberania estatal, postulando que, uma vez que cada país tem a prerrogativa de selecionar os imigrantes que quer receber, aqueles que descumprem as normas devem ser privados de qualquer proteção.

Para esta análise baseada em direitos é necessário, contudo, entender-se a questão em todas as suas facetas, compreendendo, entre outros aspectos, o dilema da pobreza em diversos países do mundo, fator que contribui para a intensificação dos fluxos migratórios irregulares. É nesse panorama que Carlos B. Vainer aponta a crueldade sistemática que permeia as migrações irregulares e seu tradicional tratamento pelos Estados:

"No mundo no qual parece se aproximar a realização plena da utopia neoliberal, muitos milhões são os deslocados compulsórios, os reassentados,

13. Somavia, Juan. Preface. ILO's multilateral framework on labour migration: non-binding principles and guidelines for a rights-based approach. OIT. Repartição Internacional do Trabalho. Genebra, 2006, p. V. Disponível em: [www.ilo.org/wcmsp5/groups/ public/---asia/---ro-bangkok/documents/publication/wcms_146243.pdf]. Acesso em: 27.04.2011. No original: "Many migrant workers, especially low skilled workers, experience serious abuse and exploitation. Women, increasingly migrating on their own and now accounting for almost half of all international migrants, face specific protection problems. In the face of rising barriers to cross border labour mobility, the growth of irregular migration, and trafficking and smuggling of human beings constitute major challenges to protection of human and labour rights". Tradução do autor. 
os refugiados e repatriados e deportados, os expulsos e clandestinos. Proibidos de ficar, confinados, interditados de entrar, obrigados a sair, eles nos dizem da natureza perversa da liberdade operada sob a hegemonia da globalização contemporânea: o mundo desterritorializado e sem fronteiras de uns é o mesmo mundo territorializado e guetificado de outros." 14

Todo esse alarmante cenário é agravado por legislações nacionais extremamente repressivas, que alimentam a intolerância e a condição marginal dos imigrantes irregulares, tornando ainda mais problemática a interação com a sociedade receptora. ${ }^{15}$

Veja-se o exemplo emblemático da legislação do estado norte-americano do Arizona, que criminalizou a condição de imigrante indocumentado, prevendo, também, prerrogativas policiais de extrema truculência. Promulgada em abril de 2010, a Lei Estadual 1.070 foi considerada autoritária e discriminatória, gerando reações no plano internacional, como o repúdio expresso da Unasul (União das Nações Sul-Americanas). ${ }^{16}$ O Governo brasileiro também se manifestou de forma contrária, publicando nota por meio do MRE. ${ }^{17}$

14. Vainer, Carlos B. As novas categorias de uma sociologia dos deslocamentos compulsórios e das restrições migratórias. In: Castro, Mary Garcia (org.). Migrações internacionais: contribuições para políticas. Brasília: CNPD, 2001, p. 182-183.

15. O debate quanto à sanção que deve ser aplicada ao imigrante irregular tem grande repercussão nos países do capitalismo central, sobretudo na Europa e Estados Unidos. Como já pontuado, existem dissensos, inclusive, quanto à criminalização da condição de imigrante irregular, dada a magnitude dos fluxos migratórios destes países. A Itália discute, atualmente, o delito de "ser imigrante ilegal", com uma iniciativa do Governo Berlusconi de criação deste tipo penal. A respeito disso, veja-se a conclusão de Stefano Rodotà, catedrático de Direito Civil na Universidade de Roma La Sapienza, publicada no periódico espanhol El País: "Se convierte en delito una simple condición personal, el hecho de ser extranjero, en contraste con lo que establece la Constitución en materia de igualdad”. Cf. Rodotá, Stefano. Italia y los 'empresarios' del miedo. Jornal El País. Disponível em: [www.elpais.com/articulo/opinion/Italia/empresarios/miedo/ elpepuopi/20080524elpepiopi_13/Tes]. Acesso em: 14.01.2011.

16. Cf. [www.bbc.co.uk/portuguese/noticias/2010/05/100504_marcia_arizona_rc. shtml]. Acesso em 04.12.2010.

17. Trecho da nota n. 278 do Itamaraty, de 03.05.2010: "O governo brasileiro recebeu com grande preocupação a notícia de que o Estado norte-americano do Arizona aprovou, em 22 de abril, legislação que criminaliza a imigração irregular. O governo brasileiro tem-se pronunciado firme e reiteradamente, em negociações bilaterais e nos foros internacionais, contra a associação indevida 


\section{A CONVEnÇÃO 143 dA OIT: PROTEÇÃO DE TOdOS OS TRABALHADORES MIGRANTES}

Um dos principais instrumentos normativos que consolidam esse rightsbased approach to labour migration é a Convenção 143 da OIT. Datada de 1975, a Convenção 143 entrou em vigor na ordem internacional em 1978 e trata das migrações em condições abusivas e promoção da igualdade de oportunidades e de tratamento dos trabalhadores migrantes.

Por meio da Convenção 143, conforme menciona Rodrigo de Lacerda Carelli, "busca a OIT a devida e igual proteção, pelo menos quanto a direitos fundamentais, a todos os trabalhadores do mundo" ${ }^{18}$ sejam eles migrantes em condição de regularidade ou irregularidade migratória.

Neste desígnio, estabelece já o art. $1 .^{\circ}$ da Convenção 143 da OIT que "os membros para os quais a presente Convenção esteja em vigor deverão comprometer-se a respeitar os direitos fundamentais do homem de todos os trabalhadores migrantes".

Assim, do artigo inaugural da Convenção 143 já se depreende aquele que é o seu grande diferencial: a inclusão dos imigrantes em condição de irregularidade no amplo grupo de trabalhadores a serem protegidos. E, mais adiante, no art. 9. ${ }^{\circ}$ do diploma, tal diretiva fica ainda mais clara:

entre migração irregular e criminalidade. No caso da nova lei do Arizona, o poder discricionário conferido aos agentes policiais para verificação da situação migratória e prisão de estrangeiros virá ao sacrifício dos direitos humanos dos migrantes. O governo brasileiro considera que conceder o mesmo tratamento a indocumentados e criminosos subverte noções elementares de humanidade e justiça. Julga que o caminho a seguir não é o da criminalização, mas o da regularização migratória, de que é exemplo a aprovação da Lei 11.961/2009, que promoveu ampla regularização da situação migratória dos estrangeiros no Brasil. O governo brasileiro se une às manifestações contrárias à lei anti-imigratória do Arizona. Espera que tal legislação seja revista, de modo a evitar a violação de direitos de milhões de estrangeiros que vivem e trabalham pacificamente nos Estados Unidos, como os brasileiros que se encontram naquele país". MRE. Nota à imprensa 278. Brasília, 2010. Disponível em: [http://www.itamaraty.gov.br/ sala-de-imprensa/notas-a-imprensa/lei-anti-imigratoria-do-arizona]. Acesso em 10.05.2011.

18. Carelli, Rodrigo de Lacerda. Trabalho do estrangeiro no Brasil. Boletim do Cedes - Centro de Estudos Direito e Sociedade. Março de 2007. Disponível em: [http:// cedes.iesp.uerj.br/PDF/cidadaniatrabalho/trabalho\% 20do\%20estrangeiro\%20no\% 20Brasil.pdf]. Acesso em: 17.07.2010. 
"(...) O trabalhador migrante, nos casos em que a legislação não tenha sido respeitada e nos quais a sua situação não possa ser regularizada, deverá beneficiar pessoalmente, assim como a sua família, de tratamento igual no que diz respeito aos direitos decorrentes de empregos anteriores em relação à remuneração, à segurança social e a outras vantagens."

Nota-se, aqui, que o tratamento da imigração irregular passa a ser tomado muito mais como uma questão de proteção aos direitos da pessoa humana do que como uma pauta puramente de segurança nacional. Frise-se, entretanto, que a Convenção não perde a dimensão do controle migratório, por exemplo, ao estabelecer que os Estados devem tomar medidas "a fim de suprimir as migrações clandestinas e o emprego ilegal de migrantes" (art. 3. ${ }^{\circ}$, $a$, da Convenção). A perspectiva baseada em direitos, contudo, dá a tônica do instrumento e revela uma postura bastante clara no sentido de proteger o trabalho prestado pela pessoa do imigrante.

Sintetizando a proteção arquitetada pela Convenção, registram Patrick Taran e Eduardo Geronimi: "o trabalhador migrante tem direitos a remuneração pelo trabalho realizado, incluindo quaisquer indenizações pagas ao término do contrato, e todos os benefícios de férias não utilizados devem ser pagos de acordo com a prática nacional, a despeito de o status ser (de imigrante) legal ou não". ${ }^{19}$

Em outras palavras, a Convenção entende a proteção trabalhista como um direito irrenunciável da pessoa humana, que não restará prejudicado em face da condição de irregularidade migratória. Esta diretiva é resultado de um processo internacional de assentamento das bases da proteção ao imigrante.

A Convenção 143 enfrenta problemas acentuados de aceitação entre os países do globo, diante da prioridade máxima que propõe na salvaguarda de direitos humanos no trabalho prestado por imigrante não documentado. São apenas $23^{20}$ ratificações até o presente momento, quase a integralidade delas por países não receptores de grandes contingentes de imigrantes. ${ }^{21}$

19. Taran, Patrick A.; Geronimi, Eduardo. Globalization, labour and migration: protection is paramount. Genebra: OIT, 2003, p. 14. No original: "Therefore, the migrant worker has rights to remuneration for work performed, including any normally paid indemnities upon termination of contract, and whatever unused annual vacation benefits may be payable according to national practice, regardless of whether status was legal or not". Tradução do autor.

20. Em agosto de 2011, conforme informação no sítio da OIT.

21. A exceção dentre os países que ratificaram a Convenção n. 143 é a Itália, que recebe um volume considerável de imigrantes. Contudo, apesar de ter ratificado 
A Convenção ainda não foi ratificada pelo Brasil, não sendo, assim, um instrumento formalmente cogente na ordem jurídica nacional.

Interessante registrar que, no mês de setembro de 2008, a Comissão Tripartite de Relações Internacionais do MTE aprovou - contando com a convergência da representação governamental, dos trabalhadores e dos empregadores - o encaminhamento da Convenção para ratificação pelo Congresso Nacional, ${ }^{22}$ empunhando a reivindicação de diversos movimentos que ao longo dos anos conclamavam pela ratificação da Convenção (como a Pastoral do Migrante, por exemplo) e denotando uma intenção sólida do Brasil em adotar o diploma. ${ }^{23}$

Pode-se afirmar que a Convenção 143 da OIT, juntamente com a Convenção 97 da mesma organização e a Convenção Internacional sobre a Proteção dos Direitos de Todos os Trabalhadores Migrantes e dos Membros das suas Famílias da ONU, de 1990, formam o sustentáculo da proteção internacional ao trabalhador imigrante. Nas palavras de Patrick Taran e Eduardo Geronimi:

"Estas três Convenções em conjunto providenciam uma definição compreensiva, baseada em valores, e a base legal para a política nacional sobre trabalhadores migrantes estrangeiros e membros de suas famílias. Elas servem, assim, como ferramentas a encorajar os Estados a estabelecerem ou aperfeiçoarem as legislações nacionais em harmonia com os padrões internacionais. Elas não são simples instrumentos de direitos humanos. Várias provisões em cada uma delas somam a uma agenda compreensiva de política nacional e de consultas e cooperação entre os Estados em formulação de políticas de migração trabalhista, troca de informações, informações a migrantes, retorno ordenado e reintegração etc." ${ }^{24}$

o instrumento, a Itália passa por um momento de verdadeira contradição na disciplina migratória, ao recrudescer suas normas internas, chegando a criminalizar a condição de imigrante irregular.

22. Vide notícia no sítio do MTE: [http://www.mte.gov.br/sgcnoticia.asp? IdConteudoNo ticia $=3732 \&$ PalavraChave $=$ imigracao, $\% 20 \mathrm{cnig}, \% 20 \mathrm{oit}]$. Acesso em: 18.07.2011.

23. A própria OIT já apontou o Brasil como um dos possíveis países a ratificarem a Convenção 143. Cf. [http://www.migrantsrights.org/ILO_report101199.htm]. Acesso em: 18.07.2010.

24. Taran, Patrick; Geronimi, Eduardo. Op. cit., p. 15. No original: "These three Conventions together provide a comprehensive 'values-based' definition and legal basis for national policy and practice regarding non-national migrant workers and their family members. They thus serve as tools to encourage States to establish or improve national legislation in harmony with international standards. They are not simply human rights instruments. Numerous provisions in each add up to a 
Esta visão juridicamente orientada éa adotada no presente ensaio, que compartilha da ideia de que a regulação internacional da matéria consolida direcionamentos que merecem imediata implementação, com a extirpação de normas nacionais que se choquem com o ideal de um tratamento humanizado à questão migratória.

\section{Conclusĩo}

As reflexões jurídicas sobre a questão migratória na atualidade demandam a construção de uma plataforma de tratamento baseada na proteção dos direitos fundamentais da pessoa humana, em todas as suas dimensões, sob o pano de fundo da solidariedade. O trabalho prestado por imigrantes, nesse contexto, é merecedor de regulação jurídica consistente, em padrões consentâneos com os avanços promovidos pelo Direito Internacional do Trabalho.

Recebem-se, aqui, influxos de duas matrizes, ambas direcionadas nesse mesmo sentido. Em primeiro lugar, a proteção à pessoa do imigrante, que não pode ser discriminada por motivo de ascendência étnica, devendo ser tomada pelo Direito em sua condição humana essencial. De outro lado, o caminhar da progressiva proteção ao trabalho, que deve ser regulado e guarnecido de direitos para o obreiro como elemento essencial para uma vida digna.

A própria noção de justiça como um exercício continuado da virtude para o outro - considerada a dimensão da aparente diferença do imigrante que, inevitavelmente, torna-se "o outro" - faz indispensável a observância a estes padrões axiológicos historicamente maturados, sob pena de um inadmissível desvio das próprias finalidades do Direito.

A regulação da matéria no plano internacional é reflexo dessa diretiva, sendo que, nas últimas décadas, foram celebrados diversos instrumentos normativos e compromissos de alcance global, regional e local que reafirmam o princípio da não discriminação e encampam o caminhar da proteção do imigrante, também por meio da salvaguarda de direitos trabalhistas. Despertou-se, aqui, aquilo que Antônio Augusto Cançado Trindade denominou "consciência jurídica universal", que determina a "prevalência da dignidade da pessoa humana em quaisquer circunstâncias". ${ }^{25}$

comprehensive agenda for national policy and for consultation and cooperation among States on labour migration policy formulation, exchange of information providing information to migrants, orderly return and reintegration, etc.". Tradução do autor.

25. Cançado Trindade, Antônio Augusto. Op. cit. No original: "en razón precisamente del despertar de la conciencia jurídica universal para la necesidad de prevalencia 
Não há, contudo, como se negar os descompassos das legislações nacionais em relação ao tema - incluindo-se, aqui, a brasileira -, vez que muitos dos países ditos desenvolvidos insistem em priorizar a dimensão da segurança nacional, tratando a imigração como questão exclusivamente policial. Tal situação, entretanto, só faz reforçar a necessidade de planos concretos de ação no sentido de tornar os compromissos internacionais realidade, como forma de implementar diretivas éticas que não admitem postergação.

A imigração em condição de irregularidade, nesse quadro, é assunto de primeira grandeza na agenda internacional, vez que milhares e milhares de seres humanos submetem-se diariamente aos riscos de cruzamentos irregulares de fronteiras nacionais na esperança de uma vida melhor (intenção que dificilmente se pode condenar).

Vindos de países pobres, pode-se afirmar que imigrantes indocumentados, não raro, são "refugiados por motivos de subsistência", ${ }^{26}$ na impactante e precisa metáfora de Cristiane Maria Sbalqueiro Lopes. Ou seja, fogem de condições de extrema pobreza e falta de perspectivas em seus países de origem para buscarem nova vida em países mais desenvolvidos, que, por sua vez, respondem de maneira geralmente recrudescida.

Assim, em relação aos imigrantes indocumentados as questões tendem a ser extremamente tormentosas, reunindo elementos de destacada sensibilidade. De toda sorte, há que se ter em mente que a condição de pessoa humana não admite ser preterida em face da condição de irregularidade migratória. Distanciar-se de avaliação dos imigrantes indocumentados como criminosos e aproximar-se da percepção deles como vítimas de uma cruel indústria da pobreza, que envolve esquemas odiosos de tráfico de pessoas e exploração de trabalho forçado, é providência essencial para a análise do tema aqui proposto.

O Brasil tem posição muito peculiar nesta dinâmica. Legatário de uma história de participação ativa de imigrantes na formação da cultura nacional, o país vive hoje um momento de mudanças na sua vocação migratória. Hoje, envia mais migrantes do que recebe, reflexo do panorama social interno. A despeito disso, o fluxo de imigrantes em condição de irregularidade oriundos, sobretudo, da América do Sul, cresce consideravelmente nas grandes cidades

de la dignidad de la persona humana en cualesquiera circunstancias”. Tradução do autor.

26. Lopes, Cristiane Maria Sbalqueiro. O direito do estrangeiro numa perspectiva de direitos humanos. Tese de doutoramento, Sevilha, Universidad Pablo de Olavide, 2007, p. 35. 
brasileiras, a ver-se pela situação dos bolivianos na capital paulista. E enunciarse, desde já, o aumento desses fluxos nas próximas décadas não parece previsão infundada.

Assim, a questão migratória decerto recuperará sua relevância na agenda jurídica nacional, sendo imperioso o alinhamento da regulação e políticas de migração nacionais às grandes linhas da disciplina internacional na matéria. Tal providência se concretiza de variadas formas, como, por exemplo, pela promulgação de um novo Estatuto do Estrangeiro, da aprovação de uma nova política migratória para o país, além da ratificação das convenções internacionais mais relevantes na matéria (como a Convenção da ONU de 1990 e a Convenção 143 da OIT). ${ }^{27}$

Desta forma, o Brasil consolidará uma postura humana e equilibrada no tratamento do tema migratório, o que deve ser aliado à participação em programas internacionais de combate ao tráfico internacional de pessoas e migrantes, além de iniciativas multidisciplinares de eliminação de toda e qualquer forma de trabalho em condição análoga à de escravo.

Trata-se, também, de uma opção estratégica para o país. Somente posicionando-se em favor da proteção humana dos migrantes documentados ou indocumentados poderá o Brasil exigir igual tratamento aos muitos de seus nacionais que se encontram irregularmente em outros países, vítimas das próprias mazelas do desenvolvimento social brasileiro.

Quanto ao trabalho prestado por imigrantes, muitos são os caminhos para uma mesma conclusão, que encampa a "finalidade primordial, historicamente determinante do direito do trabalho: a proteção dos assalariados contra todas as formas de exploração que possam sofrer", ${ }^{28}$ na lição de Jean-Claude Javillier. Seja por meio da diretiva antidiscriminatória, da aplicação da teoria trabalhista das nulidades, da universalização à proteção ao trabalho, de um direito fundamental ao trabalho digno, do caminhar dos diplomas internacionais, enfim, a resposta essencial será a de que o trabalho prestado por imigrante, esteja ele em condição de regularidade migratória ou não, merecerá ampla tutela, como única maneira de se viabilizar sua existência digna.

27. Cf., nesse sentido, Süssekind, Arnaldo Lopes. Direito internacional do trabalho. 3. ed. São Paulo: Ed. LTr, 2000, p. 363.

28. Javillier, Jean-Claude. Manual de direito do trabalho. Trad. Rita Asdine Bozaciyan. São Paulo: Ed. LTr, 1988. p. 30. 


\section{RefERÊNCIAS BibLIOGRÁFICAS}

Cançado Trindade, Antônio Augusto. Voto concorrente. Condición jurídica y derechos de los migrantes indocumentados. Opinião consultiva OC18/03. Corte Interamericana de Direitos Humanos. São José da Costa Rica, 17.09.2003. Disponível em: [www.corteidh.or.cr/docs/opiniones/seriea_18_ esp.pdf]. Acesso em: 14.07.2011.

Carelli, Rodrigo de Lacerda. Trabalho do estrangeiro no Brasil. Boletim do Cedes - Centro de Estudos Direito e Sociedade. Março de 2007. Disponível em: [http://cedes.iesp.uerj.br/PDF/cidadaniatrabalho/trabalho\%20do\%20 estrangeiro\%20no\%20Brasil.pdf]. Acesso em: 17.07.2010.

Florestano, Miguel. Da deportação. In: Freitas, Vladimir Passos de (org.). Comentários ao Estatuto do Estrangeiro e opção de nacionalidade. Campinas: Millennium, 2006.

Geronimi, Eduardo. Aspectos jurídicos del tráfico y la trata de trabajadores migrantes. Programa de Migraciones Internacionales. Genebra: OIT, 2002.

JaviLlier, Jean-Claude. Manual de direito do trabalho. Trad. Rita Asdine Bozaciyan. São Paulo: Ed. LTr, 1988.

LOPES, Cristiane Maria Sbalqueiro. O direito do estrangeiro numa perspectiva de direitos humanos. Tese de doutoramento, Sevilha, Universidad Pablo de Olavide, 2007.

Mata Machado, Edgar de Godói da. Direito e coerção. São Paulo: Unimarco, 1999.

Milesi, Rosita. O Estatuto do Estrangeiro e as medidas compulsórias de deportação, expulsão e extradição. Centro Scalabriniano de Estudos Migratórios. Maio de 2004. Disponível em: [www.migrante.org.br/artigo_ deportacao_expulsao.doc]. Acesso em: 10.08.2011.

Rodotá, Stefano. Italia y los 'empresarios' del miedo. Jornal El País. Disponível em: [www.elpais.com/articulo/opinion/Italia/empresarios/miedo/ elpepuopi/20080524elpepiopi_13/Tes]. Acesso em: 14.01.2011.

SAles, Teresa. Brasil migrante, Brasil clandestino. Revista São Paulo em Perspectiva. n. 8(1). p. 112. São Paulo: Seade, jan.-mar. 1994.

Silva, Antônio Álvares da. Flexibilização das relações de trabalho. São Paulo: Ed. LTr, 2002.

Somavia, Juan. Preface. ILO's multilateral framework on labour migration: non-binding principles and guidelines for a rights-based approach. OIT. Repartição Internacional do Trabalho. Genebra, 2006, p. V. Disponível em: [www.ilo.org/wcmsp5/groups/public/---asia/---ro-bangkok/documents/ publication/wcms_146243.pdf]. Acesso em: 27.04.2011.

Süssekind, Arnaldo Lopes. Direito internacional do trabalho. 3. ed. São Paulo: Ed. LTr, 2000. 
Taran, Patrick A.; Geronimi, Eduardo. Globalization, labour and migration: protection is paramount. Genebra: OIT, 2003.

VAiner, Carlos B. As novas categorias de uma sociologia dos deslocamentos compulsórios e das restrições migratórias. CAstro, Mary Garcia (org.). Migrações internacionais: contribuições para políticas. Brasília: CNPD, 2001.

\section{Pesouisas do Editorial}

\section{Veja também Doutrina}

- Análise da discriminação inversa frente ao princípio da proibição de discriminação em razão da nacionalidade no direito comunitário europeu, de Christiane Bernardes de Carvalho Mello - RDC/57/333;

- Contrato de trabalho do estrangeiro: duração do vínculo e restrições à liberdade de contratar, de João Armando Moretto Amarante e Euclydes José Marchi Mendonça RIASP 23/138;

- El derecho de la seguridad social para trabajadores migrantes y trabajadores informales. obligación pendiente y olvidada, de Julio Ismael Camacho Solís - RDT 138/198; e

- Proteção ao trabalhador migrante, de Arnaldo Sussekind - RDT67/3. 